\title{
Changes in fermentation and animal performance during recovery from classical diet-induced milk fat depression using corn with differing rates of starch degradability
}

\author{
L. E. Koch, T. C. Jenkins, W. C. Bridges, B. M. Koch, and G. J. Lascano* \\ Department of Animal and Veterinary Sciences, Clemson University, Clemson, SC 29634
}

\begin{abstract}
Diet-induced milk fat depression (MFD) is a multifactorial disorder that can be triggered by a variety of conditions. Feeding high amounts of starch and unsaturated fatty acids has been shown to reduce milk fat yield and composition, as well as alter ruminal biohydrogenation patterns. However, little is known about how starch degradability in the rumen influences recovery from diet-induced MFD and if production of milk fat-inhibiting isomers will persist following an episode of MFD. The objective of this study was to evaluate production performance and ruminal fermentation in cows recovering from MFD when corn with a low or high starch degradability is fed. Six ruminally fistulated Holstein cows were used in a crossover design with 2 periods. During each period, MFD was induced for 10 $\mathrm{d}$ by feeding a diet with low fiber, high starch, and high unsaturated fatty acid. The polyunsaturated fatty acid concentration of the diet during the induction phase was modified primarily through inclusion of soybean oil. Following induction, cows were switched to either a high degradable starch recovery diet (HDS) or a low degradable starch recovery diet (LDS) for $18 \mathrm{~d}$. The 7-h starch degradability was $66.5 \%$ for LDS and $87.8 \%$ for HDS. Milk was collected every $3 \mathrm{~d}$ for component and fatty acid analysis. On d 0, 4, 7, 10, 16, 22, and 28 of each period, ruminal $\mathrm{pH}$ and rumen fluid were collected every $2 \mathrm{~h}$. Milk fat yield and composition was reduced during MFD induction and progressively increased by day in both HDS and LDS during recovery. Dry matter intake was similar among treatments and increased steadily over time during recovery. Preformed fatty acids were greater for HDS-fed animals, and de novo fatty acid in milk fat was greater for LDS-fed animals. Milk trans-10 C18:1 tended to be greater for
\end{abstract}

Received November 6, 2018.

Accepted February 21, 2019.

*Corresponding author: glascan@clemson.edu
HDS, and trans-10,cis-12 conjugated linoleic acid was significantly greater for HDS. cis-9,trans-11 conjugated linoleic acid was not affected by starch degradability during recovery. Total volatile fatty acids, butyrate, and valerate tended to differ or differed with recovery treatment, but ruminal $\mathrm{pH}$ and ammonia concentration were unaffected. The HDS diet responded similarly to the LDS diet during recovery with regard to milk fat percentage, but milk and fat yield tended to consistently be lower in HDS. When considering approaches to ameliorate diet-induced MFD, the degradability of the starch within rations should be evaluated. Although animal performance was similar, some trans fatty acid isomers were persistent in the milk through the recovery phase with HDS-fed animals, suggesting that milk fat synthesis might be potentially inhibited and biohydrogenation pathways modified in the rumen following an episode of MFD.

Key words: starch degradability, milk fat depression, biohydrogenation, unsaturated fat

\section{INTRODUCTION}

Diet-induced milk fat depression (MFD) is a multifactorial disorder that continues to be a problem within the dairy industry due to multiple component pricing systems (Bailey et al., 2005). Recently, nutritional strategies with specific aims to restore milk fat yield have been investigated (Rico et al., 2015a), but it is clear that MFD can precipitate from a variety of conditions including a high rumen UFA load (RUFAL), starch level, low dietary fiber, and, subsequently, low rumen $\mathrm{pH}$. Accumulation of specific trans intermediates through rumen biohydrogenation $(\mathbf{B H})$ of UFA by rumen microbes has been linked to MFD (Baumgard et al., 2000; Piperova et al., 2000; Kairenius et al., 2015). Work by Baumgard et al. (2000) first characterized a connection between the trans-10,cis-12 CLA isomer by using postruminal infusions of pure CLA isomers and demonstrated that trans-10,cis-12 CLA decreased milk fat synthesis. 
Increased trans-isomer accumulation has been associated with microbial shifts within the rumen, most often caused by dietary modification (Rico et al., 2015b; Lascano et al., 2016). In a study by Rico et al. (2015b) where cows were fed a high-UFA diet, rapid rumen microbial shifts were observed coupled with an increase in trans-10,cis-12 CLA accumulation. Additionally, Maia et al. (2010) reported that the lag phase of Butyrivibrio fibrisolvens, a microbe that plays a major role in $\mathrm{BH}$, was increased when exposed to either linoleic acid (cis-9,cis-12 18:2) or $\alpha$-linolenic acid (cis-9,cis12,cis-15 18:3) and growth was only observed when the PUFA was converted to vaccenic acid (trans-11 18:1). This further demonstrates that rumen microorganisms are sensitive to UFA within the diet. Reductions in $\mathrm{pH}$ have been associated with a shift in the $\mathrm{BH}$ pathway of linoleic acid to stearic acid, although this is not always necessary (Lascano et al., 2016) to increase trans-10,cis-12 CLA accumulation. However, Fuentes et al. (2009) showed an increase in trans-10, cis-12 CLA as $\mathrm{pH}$ decreased from 6.5 to 5.5 using continuous culture fermenters. Cereal grain inclusion in rations is a cost-effective source of energy for high-producing dairy cows. However, fermentable carbohydrates, if not balanced correctly, can illicit low rumen $\mathrm{pH}$ conditions or even lead to the onset of subacute and acute ruminal acidosis (Danscher et al., 2015). Combinations of high RUFAL and starch have been shown to reduce milk fat to a greater extent than just by one factor alone, adding to the multifactorial nature of MFD. The amount of starch can have an effect on rumen $\mathrm{pH}$, but also the degradability of starch may play a role in $\mathrm{BH}$. Starch degradability $\left(\mathbf{S t K}_{\mathbf{d}}\right)$ varies greatly by grain type, vitreousness, and processing and can possibly alter the kinetics of microbial interactions with starch and fat in the rumen (Firkins et al., 2001; Allen et al., 2008; Lopes et al., 2009). Interestingly, Lascano et al. (2016) observed higher $\mathrm{pH}$ in rumen continuous culture fementers fed a processed corn source with a high $\operatorname{StK}_{\mathrm{d}}$ (84 vs. 48 and $66 \%$ 7-h $\mathrm{StK}_{\mathrm{d}}$ ), reporting greater trans-10 18:1 and trans-10,cis-12 CLA in continuous culture fermenters. This was a notable observation that supports the idea that the production of these isomers is not contingent on a low $\mathrm{pH}$. In addition, if dietary starch concentration and PUFA were lowered to recover cows from MFD, but $\mathrm{StK}_{\mathrm{d}}$ was not assessed, a lag might exist in the time it takes milk fat production to return to normal.

Diet-induced MFD has been studied at length (Harvatine et al., 2009b), but little research has been conducted on how to recover cows from MFD by using diets with varying starch degradabilities. Rico and Harvatine (2013) investigated the time course of induction of MFD and recovery, with induction being achieved at $9 \mathrm{~d}$ and total recovery from MFD at 19 d. Recovery was achieved by reducing dietary starch and PUFA concentration and increasing dietary fiber, and in a subsequent study diet fermentability was investigated by modifying dietary NDF, with similar results reported (Rico and Harvatine, 2013; Rico et al., 2015a). However, because starch concentration and $\mathrm{StK}_{\mathrm{d}}$ may play a role in the onset of diet-induced MFD, it is of interest to investigate whether cows receiving lower starch concentrations but high $\mathrm{StK}_{\mathrm{d}}$ will recover similarly to cows fed a low-StK $\mathrm{d}_{\mathrm{d}}$ diet. Therefore, the hypothesis of this experiment was that $\mathrm{StK}_{\mathrm{d}}$ of the main source of soluble carbohydrates in the diet will affect lactating dairy cow recovery from MFD. The objective of this study was to determine whether feeding corn sources with differing starch degradabilities during recovery from diet-induced MFD has an effect on animal performance, production, and ruminal fermentation.

\section{MATERIALS AND METHODS}

\section{Animals and Experimental Design}

Six multiparous, rumen-fistulated, lactating Holstein cows $(184.33 \pm 29.6$ DIM; $613.73 \pm 8.53 \mathrm{~kg}$ of BW) were used in a crossover design following a model used successfully to study MFD induction and recovery (Rico and Harvatine, 2013). All procedures were approved by the Clemson Institutional Animal Care and Use Committee. The experiment was divided into 2 periods each consisting of a 10-d induction phase and 18-d recovery phase (Figure 1; total length of period $=28 \mathrm{~d}$ ). All animals were fed the standard herd diet for $10 \mathrm{~d}$ before the start of the study that was used as an adaptation period for the induction phase and were then switched to a high-PUFA, low-fiber, highstarch induction diet (IND) for $10 \mathrm{~d}$ in an attempt to induce MFD. After induction, 3 cows were either assigned to a low degradable starch diet (LDS) or a high degradable starch diet (HDS) for $18 \mathrm{~d}$ to recover the animals from MFD (Table 1). Cows were assigned randomly to the recovery treatments and switched to the next treatment for the subsequent recovery phase in a crossover pattern. The primary starch source for the LDS treatment was dry ground corn, and the HDS treatment replaced half of the dry ground corn with a processed corn product (Matrix Nutrition LLC, Phoenix, AZ). This combination was chosen based on the results observed in a previous experiment using corn with different $\mathrm{StK}_{\mathrm{d}}$ (Lascano et al., 2016). The supplier of the processed corn indicated that the product underwent proprietary heat and pressure treatments to alter 
the prolamine protein structure, which eliminated the crystalline and hydrophobic properties of the vitreous unprocessed corn. The processed corn product provided a source of rapidly available starch for ruminal fermentation (Table 2).

In between the first and second periods, all cows were fed the LDS diet during a 10-d washout period, which provided $20 \mathrm{~d}$ between experimental diets and minimized the possibility of carry-over effects. Diets were mixed daily at $0700 \mathrm{~h}$, and animals were fed at $110 \%$ of daily requirements at 0800 and $1500 \mathrm{~h}$ in individual tie stalls with access to water free choice. The rations were adjusted daily to account for the corn silage DM variation as well as weekly total diet DM to maintain animals at $110 \%$ of predicted intake $\left(72 \mathrm{~h}\right.$ at $60^{\circ} \mathrm{C}$ in an air-forced oven). All animals were weighed weekly in the morning after milking and just before feeding. Orts were weighed daily, and feed was adjusted weekly based on refusals. Samples of individual ingredients were sampled weekly and DM determined daily to adjust for moisture content of corn silage.

\section{Milk and Rumen Sampling}

Cows were milked twice daily at 0600 and $1700 \mathrm{~h}$ and housed in an individual tiestall barn. Milk samples were taken every 3 d during both morning and evening milking; a.m. and p.m. samples were pooled into one daily sample proportionally based on cow milk yield for that day. Approximately $30 \mathrm{~mL}$ of the pooled sample was added to a tube containing bromopol tablets and then shipped to United DHIA (Radford, VA) to be analyzed for milk components (fat, protein, lactose, MUN). A 50-mL subsample was collected in a centrifuge tube and frozen for later fatty acid (FA) analysis. On d 0, 4, 7, and 10 of the induction phase and d 16, 22, and 28 of the recovery phase, rumen samples were sampled from 5 places in the rumen (central, caudal, dorsal, ventral, and cranial) at $0,2,4,6,8,10,12,14,16,18,20$, and $22 \mathrm{~h}$ after the $0800 \mathrm{~h}$ feeding. Samples were mixed in a common container and strained through 2 layers of cheesecloth to obtain the liquid fraction. Immediately after straining, $\mathrm{pH}$ was measured and recorded using a pH-specific electrode meter (Hanna Instruments, Woonsocket, RI). The strained rumen fluid $(5 \mathrm{~mL})$ was added to a centrifuge tube containing $1 \mathrm{~mL}$ of metaphosphoric acid, and then, the sample was frozen for subsequent VFA and $\mathrm{NH}_{3}-\mathrm{N}$ analysis. Methods for VFA and $\mathrm{NH}_{3}-\mathrm{N}$ sample preparation were conducted according to the methods of Moody et al. (2007). Another 5 $\mathrm{mL}$ of strained rumen fluid was added in a 1:1 ratio with a formaldehyde-methyl green solution for protozoal enumeration and identification and stored at $4^{\circ} \mathrm{C}$.

\section{Sample Analysis}

Feed samples and orts were dried in a forced-air oven at $60^{\circ} \mathrm{C}$ for $72 \mathrm{~h}$ and then ground to $1 \mathrm{~mm}$ through

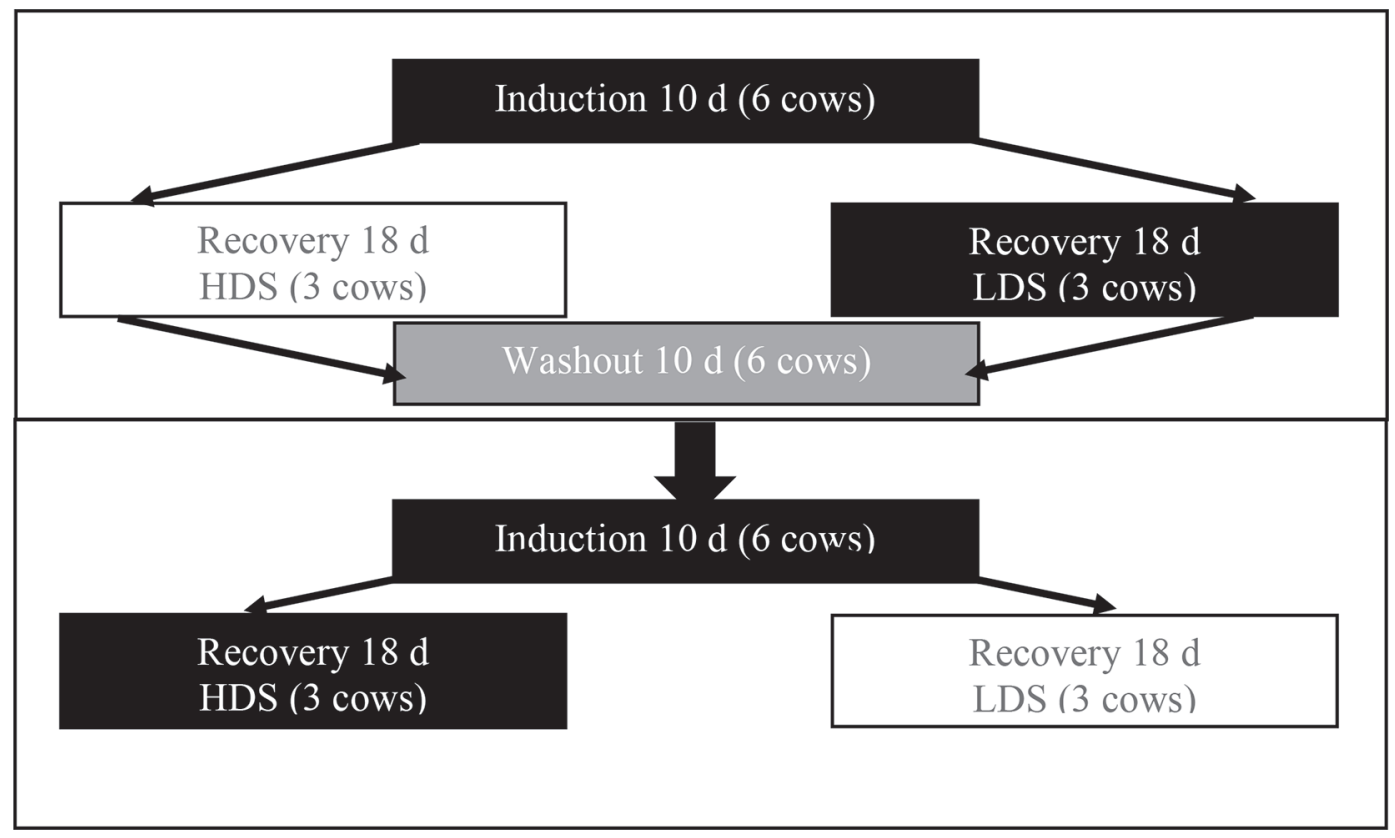

Figure 1. Experimental treatment sequence for a crossover design investigating the effect of high (HDS) or low (LDS) starch degradability during recovery. Cows were switched to the next recovery treatment during recovery of period 2 so that no cow received the same recovery diet twice. 
Table 1. Ingredient and nutrient composition of induction (IND) or recovery diets [with low degradable starch (LDS) and high degradable starch (HDS)] fed to lactating Holstein cows

\begin{tabular}{|c|c|c|c|}
\hline \multirow[b]{2}{*}{ Item } & \multirow{2}{*}{$\begin{array}{c}\text { Induction } \\
\text { IND }\end{array}$} & \multicolumn{2}{|c|}{ Recovery } \\
\hline & & LDS & HDS \\
\hline \multicolumn{4}{|l|}{ Ingredient, $\%$ of DM } \\
\hline Corn silage $^{1}$ & 37.9 & 46.3 & 46.3 \\
\hline Chopped hay ${ }^{2}$ & 0.9 & 3.0 & 3.0 \\
\hline Ground corn & 22.8 & 9.8 & 4.9 \\
\hline Processed $\operatorname{corn}^{3}$ & 0.0 & 0.0 & 4.9 \\
\hline Soybean meal, heat treated ${ }^{4}$ & 1.5 & 6.1 & 6.1 \\
\hline Soybean meal, solvent extract $(47.5 \%$ CP) & 11.4 & 7.0 & 7.0 \\
\hline Citrus pulp & 8.7 & 7.8 & 7.8 \\
\hline Roasted soybean & 5.4 & 5.4 & 5.4 \\
\hline Soybean oil & 1.7 & 0.0 & 0.0 \\
\hline Urea $^{5}$ & 0.5 & 0.5 & 0.5 \\
\hline Bakery by-product & 4.7 & 9.5 & 9.5 \\
\hline Molasses cane & 2.8 & 2.8 & 2.8 \\
\hline Mineral-vitamin $\operatorname{mix}^{6}$ & 1.7 & 1.7 & 1.7 \\
\hline \multicolumn{4}{|l|}{ Nutrient, \% of DM unless noted } \\
\hline $\mathrm{DM}$ & 94.3 & 94.3 & 94.4 \\
\hline $\mathrm{CP}$ & 15.6 & 15.0 & 15.7 \\
\hline $\mathrm{NDF}$ & 27.1 & 33.0 & 33.3 \\
\hline $\mathrm{ADF}$ & 15.6 & 20.2 & 20.2 \\
\hline Starch & 28.0 & 23.5 & 22.5 \\
\hline Total fatty acids & 7.5 & 5.2 & 5.1 \\
\hline $\mathrm{C} 18: 1$ (total) ${ }^{7} \mathrm{~g} / \mathrm{d}$ & 355 & 226 & 216 \\
\hline $\mathrm{C} 18: 2 \mathrm{n}-6, \mathrm{~g} / \mathrm{d}$ & 735 & 440 & 418 \\
\hline $\mathrm{C} 18: 3, \mathrm{~g} / \mathrm{d}$ & 61.1 & 56.5 & 55.8 \\
\hline RUFAL $^{8}$ & 5.9 & 3.2 & 3.1 \\
\hline 7-h starch degradability, ${ }^{9} \%$ of starch & 74.8 & 66.5 & 87.8 \\
\hline
\end{tabular}

${ }^{1}$ Corn silage contained $26 \%$ DM (as fed), $52.8 \%$ NDF, $23.2 \%$ starch, and $7.8 \%$ CP on a DM basis.

${ }^{2}$ Chopped hay was a combination of coastal bermudagrass and ryegrass baleage that contained $76.3 \%$ DM (as fed), $65.3 \% \mathrm{NDF}, 1.2 \%$ starch, and $12.6 \% \mathrm{CP}$ on a DM basis.

${ }^{3}$ Matrix Nutrition (Chandler, AZ).

${ }^{4}$ SoyPlus (West Central Soy, Ralston, IA).

${ }^{5}$ Optigen (Alltech, Nicholasville, KY).

${ }^{6}$ Mineral-vitamin mix contained (as-fed basis) $28.5 \%$ potassium sulfate, $19 \%$ calcium phosphate monobasic, $19 \%$ limestone, $14.26 \%$ salt, $9.5 \%$ calcium phosphate dibasic, $4.75 \%$ vitamin ADE premix, $2.85 \%$ magnesium oxide, $0.19 \%$ copper oxide, $0.95 \%$ calcium carbonate, $0.48 \%$ magnesium sulfate, $0.38 \%$ zinc sulfate. Composition (DM basis): $12.5 \% \mathrm{Ca}, 5.7 \% \mathrm{P}, 2.4 \% \mathrm{Mg}, 11.7 \% \mathrm{~K}, 5.4 \% \mathrm{~S}, 5.7 \% \mathrm{Na}, 9.1 \% \mathrm{Cl}, 1,428.7 \mathrm{mg} / \mathrm{kg}$ of $\mathrm{Cu}, 1,395.4 \mathrm{mg} / \mathrm{kg}$ of $\mathrm{Zn}, 3,627.9 \mathrm{mg} / \mathrm{kg}$ of Fe, $114.1 \mathrm{kIU} / \mathrm{kg}$ of vitamin $\mathrm{A}, 38.0 \mathrm{kIU} / \mathrm{kg}$ of vitamin $\mathrm{D}$, and $0.475 \mathrm{kIU} / \mathrm{kg}$ of vitamin $\mathrm{E}$.

${ }^{7} \mathrm{Sum}$ of cis-9 $\mathrm{C} 18: 1$ and cis-11 C18:1.

${ }^{8}$ Sum of C18:1, C18:2, and C18:3 expressed as \% DM.

${ }^{9}$ Conducted at Cumberland Valley Analytical Services (Waynesboro, PA).

Table 2. Composition of processed and unprocessed corn sources used in the low degradable starch (LDS) and high degradable starch (HDS) treatment diets during the recovery phase

\begin{tabular}{lrc}
\hline Item & $\begin{array}{c}\text { Ground } \\
\text { corn }\end{array}$ & $\begin{array}{c}\text { Processed } \\
\text { corn }^{1}\end{array}$ \\
\hline DM, \% & 88.5 & 90.4 \\
CP, \% of DM & 9.8 & 7.7 \\
Soluble protein, \% of DM & 1.5 & 1.1 \\
ADF, \% of DM & 3.9 & 4.0 \\
NDF, \% of DM & 13.1 & 16.5 \\
Starch, \% of DM & 72.0 & 73.1 \\
7-h starch degradability, ${ }^{2}$ \% of starch & 44.3 & 75.3 \\
\hline
\end{tabular}

${ }^{1}$ Processed corn source was supplied by Mark Holt of Matrix Nutrition LLC (Chandler, AZ).

${ }^{2}$ Starch degradability was analyzed using a 7 -h in vitro incubation by Cumberland Valley Analytical Services (Waynesboro, PA). a Wiley Mill (Arthur H. Thomas, Philadelphia, PA). Neutral detergent fiber, ADF, and lignin were determined according to Van Soest et al. (1991) with heatstable $\alpha$-amylase and sodium sulfite used in the NDF procedure. Dry matter was determined daily on the TMR and the ingredients (AOAC, 1990). Starch was analyzed on reground samples $(<0.5-\mathrm{mm}$ screen) using an enzymatic procedure (Bach Knudson, 1997). Starch degradability was conducted by Cumberland Valley Analytical Services (Waynesboro, PA) and determined by a 7 -h in vitro procedure outlined by Sveinbjörnsson et al. (2007). In short, feed samples were ground through a 4-mm screen and incubated in rumen fluid from earlyto mid-lactation cows fed a high-group TMR. After a 
7-h incubation time, residual starch was analyzed using enzymatic methods according to Richards et al. (1995).

Milk samples were analyzed for components by a Fossomatic (Foss Electric, Hillerod, Denmark) by United DHIA. Frozen milk samples were lyophilized, and then, FA were converted to methyl esters by direct transesterification in sodium methoxide and methanolic $\mathrm{HCl}$ (Jenkins, 2010). Individual fatty acid quantities were determined on a Shimadzu-2010 gas chromatograph with flame ionization detector and equipped with a SLB-IL111 (Sigma-Aldrich Inc., St. Louis, MO) fused silica capillary column (length $\times$ inside diameter $=$ $100 \mathrm{~m} \times 0.25 \mathrm{~mm})$ with a $0.2-\mu \mathrm{m}$ film thickness. The initial temperature was held at $140^{\circ} \mathrm{C}$ for $3 \mathrm{~min}$ and then increased $3.7^{\circ} \mathrm{C} / \mathrm{min}$ up to $220^{\circ} \mathrm{C}$ and held at that temperature for $20 \mathrm{~min}$. The carrier gas was helium supplied at $20 \mathrm{~cm} / \mathrm{s}$. Fatty acid peaks were identified and separated by comparison of the retention times to known standards (47080-U, Sigma-Aldrich Inc.; 35079, Restek, Bellefonte, PA; 1131 cis/trans FAME Mix, Matreya LLC, State College, PA)

Rumen samples were centrifuged at $40,000 \times g$ for 20 min at $4^{\circ} \mathrm{C}$. After centrifugation, $1 \mathrm{~mL}$ of the supernatant was combined with $100 \mu \mathrm{L}$ of internal standard (86 $\mu \mathrm{mol}$ of 2-ethylbutyric acid $/ \mathrm{mL}$ ) in a $\mathrm{GC}$ vial. Samples for VFA were then analyzed by GC-flame-ionization detection according to the methods of Yang and Varga (1989) and injected into a Hewlett-Packard 6890 gas chromatograph (San Jose, CA) equipped with a custom packed column $(2 \mathrm{~m} \times 0.32 \mathrm{~cm} \times 2.1 \mathrm{~mm}$ ss; $10 \%$ SP-1200/1\% $\mathrm{H}_{3} \mathrm{PO}_{4}$ on 80/100 Chromosorb WAW). Another $1 \mathrm{~mL}$ of the supernatant was placed in a $2-\mathrm{mL}$ Eppendorf microcentrifuge tube and used for analysis of $\mathrm{NH}_{3}-\mathrm{N}$ according to the methods of Chaney and Marbach (1962). Rumen protozoa were counted using a Fuchs-Rosenthal counting chamber according to the methods of Hristov et al. (2001) and later identified using methods previously outlined by Dehority (1993). Each sample preparation was counted in duplicate and repeated if either value differed from the average by more than $10 \%$. Six of the major protozoa genera were identified and counted including Entodinium spp., Epidinium spp., Diplodinium spp., Dasytricha spp., Isotricha spp., and Orphryoscolex spp.

\section{Statistics}

Statistical analyses were conducted in SAS version 9.4 for Windows (SAS Institute Inc., Cary, NC) using the MIXED procedure. The model was

$$
\begin{aligned}
Y_{i j k l m n}=\mu & +P_{j}+C_{k}\left(S_{i}\right)+X_{l}+T_{m}+D_{n} \\
& +T_{m} \times D_{n}+e_{i j k l m n}
\end{aligned}
$$

where $Y_{i j k l m n}$ is the variable of interest, $\mu$ is the overall mean, $P_{j}$ is the random effect of period ( $j=1$ to 2 ), $C_{k}\left(S_{i}\right)$ is the random effect of cow $C_{k}$ nested in sequence $S_{i}(k=1$ to 6$), X_{l}$ is the fixed effect of the pretrial adaptation period used for the induction phase or d 10 of the induction phase as a covariate for the recovery phase, $T_{m}$ is the fixed effect of treatment $(m=1$ to $2), D_{n}$ is the fixed effect of day $(n=1$ to 7$), T_{m} \times$ $D_{n}$ is the interaction of treatment and day, and $e_{i j k l m n}$ is the residual error. The model was adapted from a previous study that used a milk fat induction and recovery model to asses diet fermentability (Rico et al., 2015a). Rumen ammonia, VFA, and $\mathrm{pH}$ were analyzed as repeated measures (Littell et al., 1998) with autogregressive (AR1) or variance component (VC) covariance structures chosen as the best fit for the model. The Kenward-Rogers denominator degrees of freedom adjustment was used. Least squares means are presented in tables, with significance and tendencies declared at $P \leq 0.05$ and $P \leq 0.15$, respectively. Interactions discussed in this paper were significant if $P \leq 0.10$ and considered a tendency if $P \leq 0.15$.

\section{RESULTS AND DISCUSSION}

\section{Induction of MFD}

Diet ingredients and nutrient composition are listed in Table 1. To induce MFD, a high-oil (high RUFAL; $5.90 \%$ DM), high-starch, and low-fiber diet was used. Milk fat depression was intentionally induced by the use of soybean oil within the grain mix to increase the RUFAL. The study design allowed for an induction phase of $10 \mathrm{~d}$ followed by an 18-d recovery phase. Several studies have used this induction and recovery experimental model where milk fat has been reduced to near maximal levels in $9 \mathrm{~d}$ by feeding a low-fiber and high-UFA diet (Rico and Harvatine, 2013; Rico et al., 2014, 2015a,b).

Dry matter intake decreased from d 0 to 10 (Figure $2 \mathrm{~A})$. A similar response with DMI during IND and recovery was also reported by Rico and Harvatine (2013). Dry matter intake is commonly thought to be limited by increasing NDF content in the diet due to the rumen fill (Allen, 2000). However, in the case of the decline in DMI during IND, a possible association with the energy density exists due to the high starch and PUFA nature of the diet (Harvatine and Allen, 2006b). Dietary fat has been reported to be a potent stimulator of cholecystokinin, which has been related to satiety (Allen, 2000). Cholecystokinin suppresses feed intake by inhibiting gastric emptying, which may also stimulate tension receptors in the reticulorumen, thereby limiting intake (Allen, 2000). Similarly, high-starch diets 
increase ruminal propionate production and flux to the liver, stimulating hepatic oxidation and generation of ATP, which can also reduce DMI (Bradford and Allen, 2005; Albornoz and Allen, 2018). Ramirez Ramirez et al. (2015) and Harvatine and Allen (2006a) reported reductions in DMI with high PUFA intake. Harvatine et al. (2009b) suggested that under MFD conditions as a result of the reduction in milk energy output, energy can be partitioned toward body reserve replenishment. In the present study, even though animals were ap- proaching late lactation, DMI was noticeably reduced during IND and linearly increased during the recovery period and energy seemed to be partitioned toward milk yield because BW was not affected.

Milk fat concentration averaged $3.75 \pm 0.3 \%$ at the beginning of the induction phase and dropped to $2.34 \pm$ $0.22 \%$ by d 10 of IND; after cows were on the IND diet for $7 \mathrm{~d}$, milk fat concentration was reduced by $25 \%$ and reached a nadir after $10 \mathrm{~d}$ with a $31 \pm 5.4 \%$ reduction in milk fat concentration (Figure $2 \mathrm{~B}$ ). These reductions
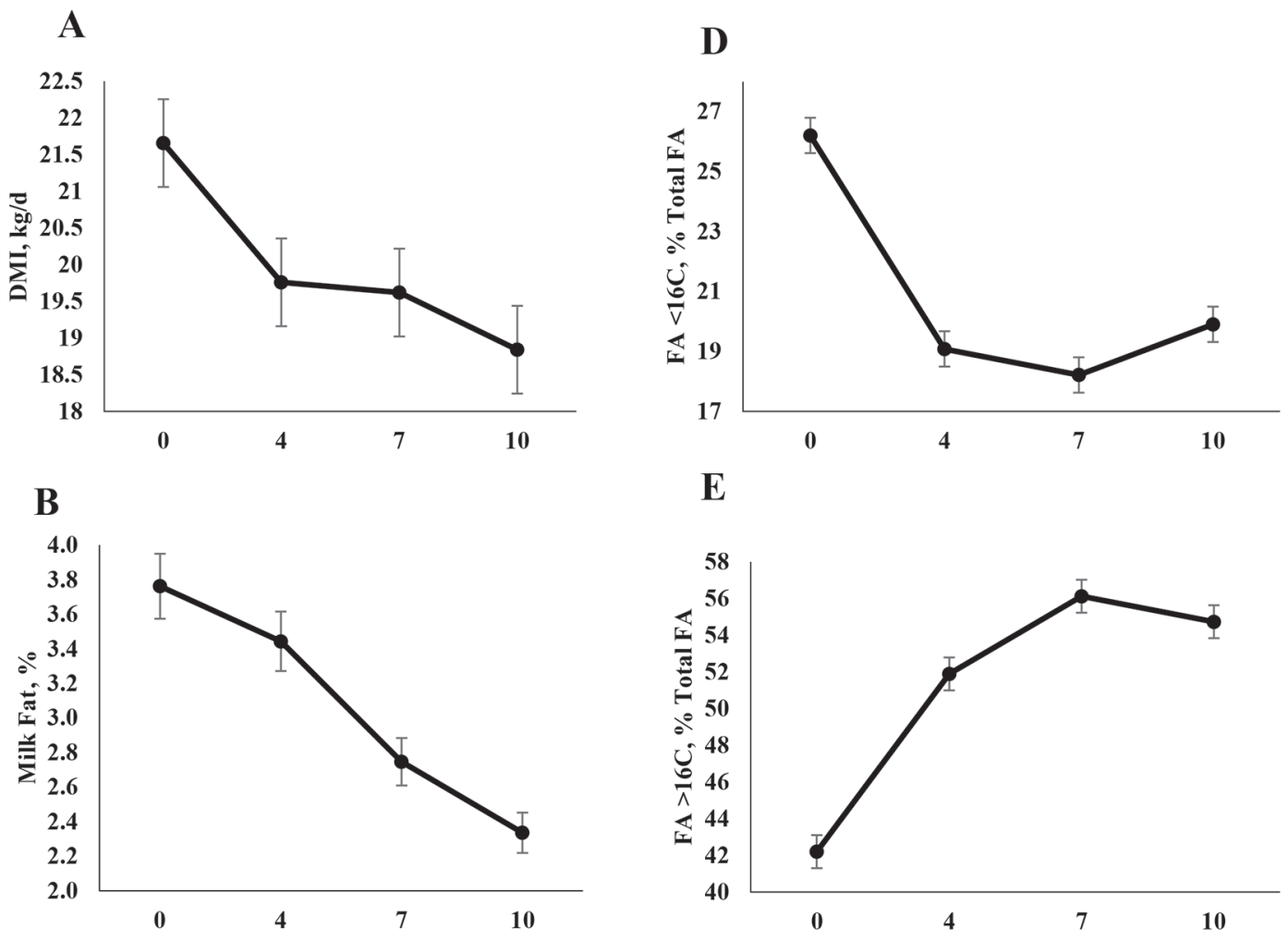

C
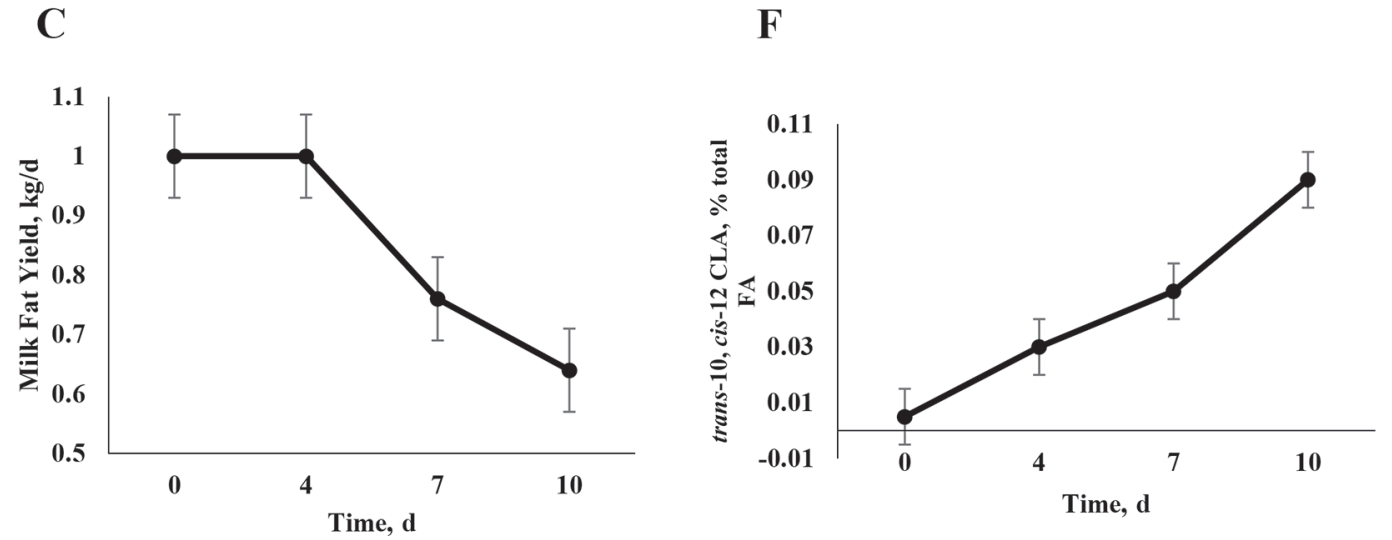

Figure 2. Induction-phase responses on DMI, milk fat (\%), milk fat yield, fatty acids (FA) <16C, FA >16C, and trans-10, cis-12 CLA. The induction phase successfully reduced milk fat yield and de novo FA and increased preformed FA. Error bars indicate SE. 
during the IND phase reflected a significant effect of day $(P<0.01)$ and were consistent with responses seen during induction of MFD (Rico et al., 2015a). Rico and Harvatine (2013) first published the time course of induction and recovery of MFD and reported that cows receiving a high-PUFA and low-fiber diet decreased milk fat percentage and yield progressively by $\mathrm{d} 3$ and 5 yet did not differ in milk yield or other components (Figures 2B, 2C). No effect of treatment existed during IND, as all animals were consuming the same diet before being assigned to treatments for the recovery phase. The number of reports is extensive of MFD induced by sources of high starch degradability, such as high-moisture corn (Bradford and Allen, 2004), ground barley (Mohammed et al., 2010), and steam-flaked corn (Mathew et al., 2011), for example. High starch degradability is not necessarily a direct cause of MFD but is considered a risk factor due to the high fermentability that can drop $\mathrm{pH}$ and alter bacterial populations that may favor accumulation of some milk fat inhibitors (Jenkins et al., 2003; Lascano et al., 2016).

Milk yield remained unchanged by treatment throughout the duration of IND. Rico and Harvatine (2013) reported no change in milk yield during induction of MFD, which is consistent with other reports on MFD (Baumgard et al., 2000; Bauman and Griinari, 2001) and one of the defining characteristics of the disorder in that milk yield is often unaffected but milk fat is reduced. De novo FA were decreased over time during IND (Figure 2D; $P<0.01$ ). This response was expected due to reduced de novo FA being a characteristic occurance in diet-induced MFD (Shingfield et al., 2006; Gama et al., 2008; Rico and Harvatine, 2013). Short- and medium-chain FA (4 to 14 carbons) as well as some of the 16-carbon FA come from de novo synthesis via acetate and $\beta$-hydroxybutyrate (Harvatine et al., 2009a). These de novo FA contribute to approximately half of the milk FA, with the remaining half being preformed (FA $>16$ carbons). A meta-analysis conducted by Maxin et al. (2011) reported that acetate infusions linearly increased milk fat yield and concentration. More recently, Urrutia and Harvatine (2017) ruminally infused acetate and observed a quadratic increase in milk fat yield, with the largest increase being in the de novo and $16 \mathrm{C}$ FA fractions. Simultaneously, preformed FA increased as MFD was induced (Figure 2E); preformed FA are derived from the diet by absorption from the digestive tract or mobilization from body reserves (Palmquist, 2006). Reductions in de novo and preformed FA are a common observation during MFD, but often de novo are the most markedly reduced (Peterson et al., 2002; Rico and Harvatine, 2013; Rico et al., 2014). Rico et al. (2014) observed a decrease in de novo FA during induction of MFD, followed by an increase in de novo FA during recovery. This is characteristic of diets high in PUFA, where a greater proportion of FA in the milk are derived from the preformed FA pool, resulting in less de novo FA production.

During IND, higher quantities of trans-10, cis-12 CLA were observed (18-fold from beginning to end of IND phase) that were similar to what has been reported in the literature (Figure 2F; Supplemental Table S1, https: //doi.org/10.3168/jds.2018-15953; Jenkins and Harvatine, 2014). Trans-10,cis-12 CLA has been reported as one of the primary isomers associated with MFD and is part of the altered BH pathway in the rumen. Increased amounts of trans-10, cis-12 CLA are commonly detected in the milk of cows with MFD. It has been observed that small quantities of trans-10,cis-12 CLA can cause the onset of MFD. As little as $3.5 \mathrm{~g} / \mathrm{d}$ has been shown to reduce milk fat by $25 \%$ (Baumgard et al., 2000).

\section{Recovery of MFD}

DMI and Milk Composition and Yield. The LDS and HDS diets contained on average $45 \%$ corn silage, $2.9 \%$ chopped hay, $9.6 \%$ ground corn or processed corn, and $41.2 \%$ of a grain mix on a DM basis that was formulated to be similar to a high-group ration. To manipulate $\mathrm{StK}_{\mathrm{d}}$, the HDS diet contained $4.8 \%$ dry ground corn and $4.8 \%$ processed corn with greater $\mathrm{StK}_{\mathrm{d}}$ (Table 2). Recovery diets were formulated without the addition of soybean oil (low RUFAL; $3.20 \%$ DM), to correct dietary PUFA level, a lower starch level, and greater forage inclusion.

Dry matter intake increased consistently from d 16 to 28 (Table 3). The increase in DMI over time during the recovery phase is consistent with that observed in rations with a higher forage inclusion and lower energy density (Whitlock et al., 2003; Martinez et al., 2009; Weiss and Pinos-Rodriguez, 2009). Oba and Allen (2003a) reported that greater starch digestibilility can increase milk yield if DMI is maintained and if extra energy is not directed to reserves due to insulin signaling. Although DMI increased following the induction phase, no statistical differences existed between treatments during the recovery phase for DMI, milk composition, milk yield, or feed efficiency. A tendency $(P=0.09)$ existed for greater milk protein in HDS-fed animals on $\mathrm{d} 22$. It is possible that the greater milk protein with the HDS treatment is due to greater substrate availability for microbial protein synthesis and leads to an increased absorption of AA in the intestine. Feeding starch sources with different rates of degradability also can influence the site of digestion, with dry ground corn having greater intestinal starch digestion 
Table 3. Milk composition and yield during recovery from diet-induced milk fat depression using a low degradable starch (LDS) or high degradable starch (HDS) diet

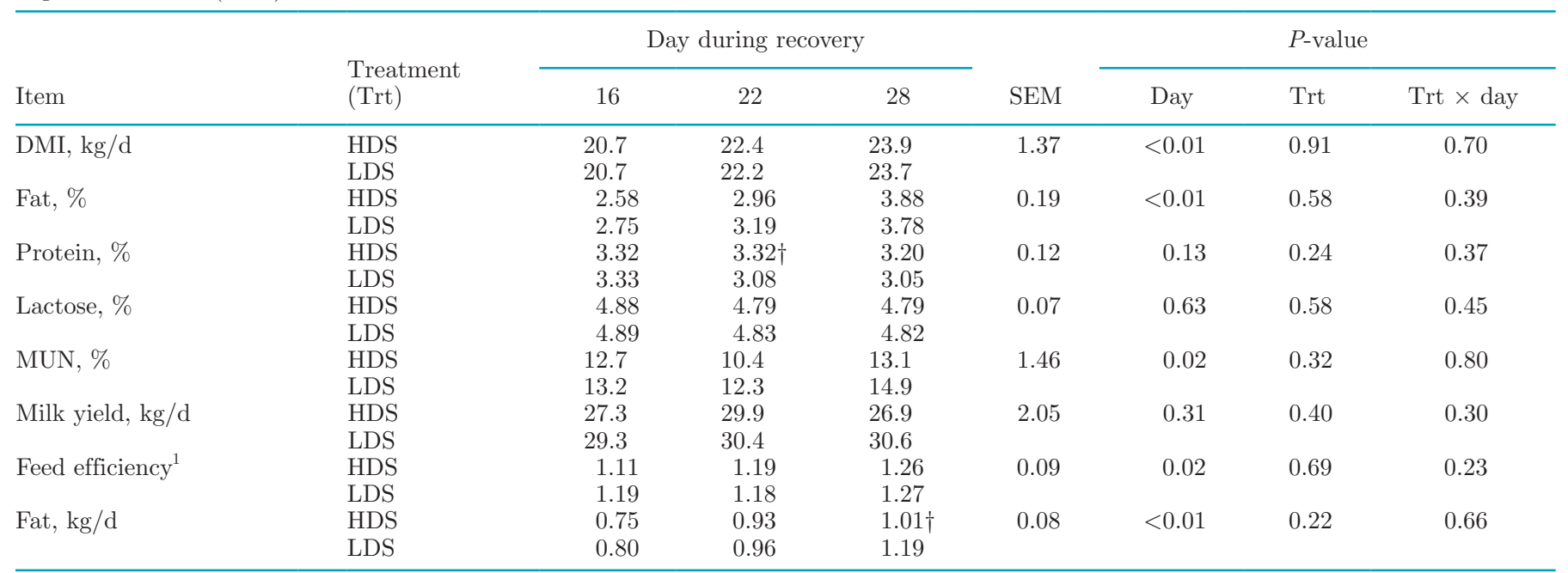

${ }^{1}$ Calculated as ECM/DMI.

$\dagger$ Tended to differ $(P<0.15)$ at the given time point.

and microbial N production (Oba and Allen, 2003b). However, microbial protein synthesis was not measured in this study, and it can only be speculated that it was influenced by the substrate availability in the HDS treatments. Following the IND phase, milk fat yield and concentration increased progressively over time in both HDS and LDS treatments (Figures 3B, 3C). Overall, milk fat yield was numerically greater for LDS-fed animals, and fat yield tended $(P=0.07)$ to be greater for the LDS-fed animals on d 28. This is consistent with findings of Albornoz and Allen (2018), who reported a reduction in milk fat yield with high-moisture corn feeding in the early postpartum period. Oba and Allen (2003a) reported an interaction of corn grain conservation method and dietary starch concentration on milk fat concentration and milk fat yield, suggesting that milk fat is most markedly affected when dietary starch is elevated and the source of starch is rapidly fermentable. An ideal balance of ruminal starch digestibility is dependent on the dietary starch concentration as well as the overall fermentability of the diet. Interestingly, even though the 7-h $\mathrm{StK}_{\mathrm{d}}$ of the corn increased from $66.7 \%$ (LDS) to $87.8 \%$ (HDS), milk fat concentration was not affected by treatment (3.78 vs. $3.88 \pm 0.19 \%$ ), and the decrease in milk fat yield observed in the HDS recovery treatment on d 28 seems to be driven by a depression in milk yield (Figure 3A), resulting in numerically lower milk yield and subsequently less fat. Another possible explanation for the reduced fat yield on d 28 is the persistence of elevated trans-10, cis- 12 CLA observed in the milk (Table 4). Also, the time below $\mathrm{pH} 6$ was significantly $(P=0.04)$ greater on $\mathrm{d}$
28 (Table 5), which could have maintained the growth of trans-10,cis-12 CLA-producing microbes. Rico et al. (2015a) observed a reduction of trans-10,cis-12 CLA during the first $6 \mathrm{~d}$ of recovery from MFD but a greater concentration compared with control for the remainder of recovery, suggesting an attenuation of the alternate $\mathrm{BH}$ pathway. This response is similar to what was observed in the present study and could be due to the fermentability of the diet, causing a lag in resumption of the normal $\mathrm{BH}$ pathway and microbial populations. Thus, even when milk fat percentage is not affected by $\mathrm{HDS}, \mathrm{StK}_{\mathrm{d}}$ can interfere with fat yield. It is important to highlight that the responses seen during this experiment were the result of including processed corn only at $50 \%$ of the corn in the HDS treatment and suggests that higher inclusion rates might result in more extreme effects.

Milk FA Composition. No significant treatment $\times$ day interactions for the concentration of de novo or preformed FA were observed in the present study (Table 4). Fatty acid isomers cis-10,trans-12 and trans- 9 , cis- 11 were not detected in our analysis and, therefore, could not be reported. Other relevant isomers are presented in Table 4. Milk de novo FA (FA $<16$ carbons) concentration was greater for LDS-fed animals when compared with those fed the HDS treatment $(P=0.04)$. Preformed FA concentrations tended to decrease during the recovery phase and were greater in HDS-fed animals when compared with LDS-fed animals $(P=$ $0.01)$. The preformed FA in milk during recovery were expected to decrease, due to the reduction in supply of PUFA in the recovery diets. Interestingly, the HDS 
treatment had a greater persistency of preformed FA in milk (maintaining same concentration from 16 to 28 d), indicating that the HDS diet is providing a greater
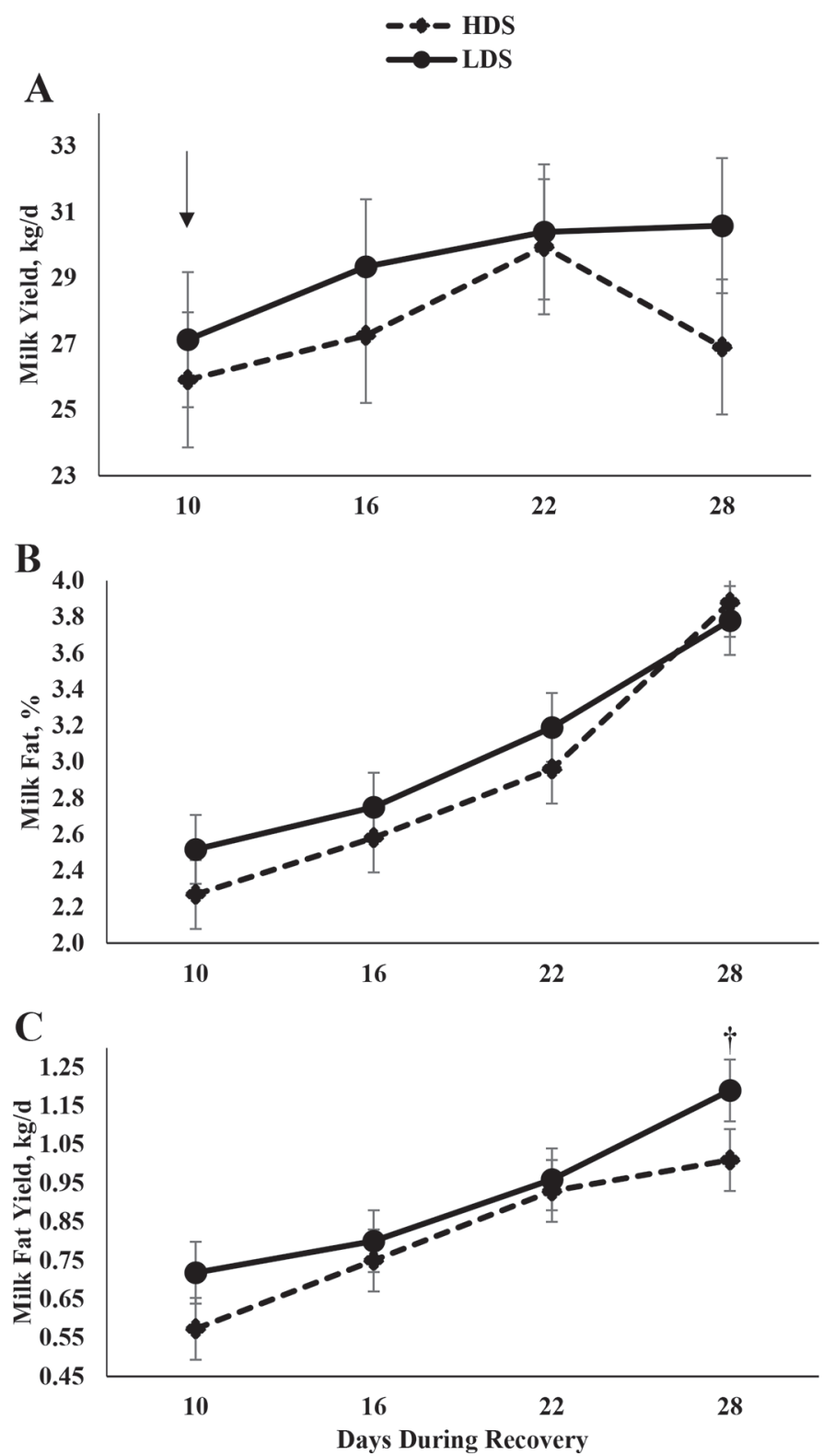

Figure 3. Effects of feeding high (HDS) or low (LDS) degradable starch diets on recovery from diet-induced milk fat depression. (A) Mean milk yield values in cows by day for the LDS and HDS treatments over the course of recovery. (B) Mean milk fat concentration by day for the LDS and HDS treatments over the course of recovery. (C) Mean milk fat yield by day for the LDS and HDS treatments over the course of recovery. The arrow represents the end of induction and start of recovery. $†$ Means tended to differ $(P<0.15)$ at the given time point. LDS = low starch degradability diet containing only unprocessed corn; HDS $=$ high starch degradability diet using a 50:50 mix of unprocessed and processed corn. Error bars indicate SE. amount of preformed FA, potentially by altering the FA flow to the duodenum through increased dietary fiber digestibility (Lascano et al., 2016) or influencing FA rate of degradation in the rumen. Furthermore, a decrease in de novo synthesis is commonly associated with an increase in preformed FA (Rico et al., 2014). Milk 16C FA did not differ by day or treatment throughout the duration of this study. Alterations in de novo and preformed FA are characteristics commonly reported in studies investigating $\mathrm{MFD}$, with de novo FA decreasing during MFD and the preformed FA increasing significantly (Ramirez Ramirez et al., 2015; Rico et al., 2015a). These results suggest that $\mathrm{StK}_{\mathrm{d}}$ represents a factor that may inhibit full recovery from MFD.

During recovery, trans-10,cis-12 CLA was significantly $(P=0.02)$ greater in the HDS-fed animals, with significance existing primarily during d 16 and 28. Similarly, other experiments have reported no effects on rumen $\mathrm{pH}$ but increased rumen accumulation of trans-10 isomers when dry and lactating cows were fed a high-fat and high-starch diet (Zened et al., 2013; Ramirez Ramirez et al., 2015). The increase in trans10,cis-12 CLA on d 28 coincides with the concordant reduction in milk fat yield on d 28 in HDS-fed animals. Trans-10,cis-12 CLA is considered to be one of the most potent inhibitors of milk fat synthesis (Shingfield and Griinari, 2007). The reduction in trans-10,cis-12 CLA from d 10 to 16, maintaining constant levels throughout the recovery phase, and the increase in de novo FA for the LDS treatment suggest that the rumen may be shifting back to the normal BH pathway in LDS-fed animals, whereas HDS resulted in a greater level of this potent milk fat inhibitor throughout this phase.

Concurrent with the increase in trans-10,cis-12 CLA, a tendency $(P=0.11)$ existed for trans-10 C18:1 to be greater for HDS when compared with the LDS treatment and also greater for HDS on $\mathrm{d} 22$. The increase in trans-10 C18:1 on d 22 does not coincide with an increase in trans-10,cis-12 CLA as expected. This could be attributed to an increase in the hydrogenation of the cis-12 double bond during $\mathrm{BH}$, suggesting that on d 22, there was a greater efficiency of BH leading to stearate. The increase in preformed FA on d 22 supports this explanation in that a portion of the change in preformed FA observed could be due to increased flow of C18:0 to the small intestine and subsequent incorporation into milk. Changes in trans-10 C18:1 are often linked to cases of MFD and altered $\mathrm{BH}$ in the rumen due to trans-10 C18:1 being an intermediate in the alternate BH pathway (Lascano et al., 2016). Although it is not a direct cause of MFD, it is often used as a proxy for cases of MFD and persistence of the altered BH path- 
Table 4. Fatty acid (FA) composition of milk during recovery from diet-induced milk fat depression using a low degradable starch (LDS) or high degradable starch (HDS) diet

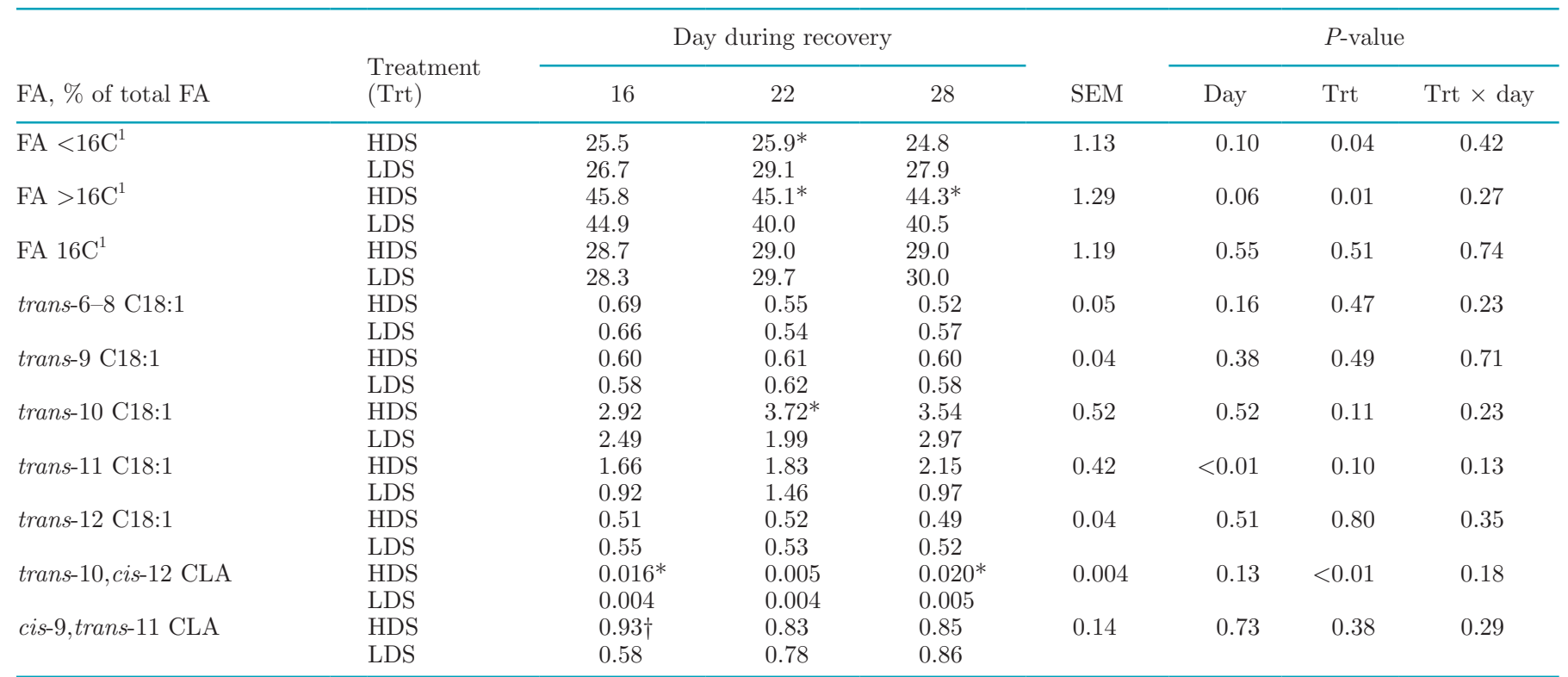

${ }^{1}$ Fatty acids $<16 \mathrm{C}$ originate from de novo FA synthesis in the mammary gland, $>16 \mathrm{C}$ FA originate from plasma, and $16 \mathrm{C}$ originate from both sources

*Significantly different $(P \leq 0.05)$ at the given time point.

$\dagger$ Tended to differ $(P<0.15)$ at the given time point.

Table 5. Fermentation parameters during recovery from diet-induced milk fat depression using a low degradable starch (LDS) or high degradable starch (HDS) diet

\begin{tabular}{|c|c|c|c|c|c|c|c|c|}
\hline Item & $\begin{array}{l}\text { Treatment } \\
\text { (Trt) }\end{array}$ & \multicolumn{3}{|c|}{ Day during recovery } & SEM & \multicolumn{3}{|c|}{$P$-value } \\
\hline Total VFA, $\mathrm{m} M$ & LDS & 111 & 117 & 117 & & & & \\
\hline \multicolumn{9}{|l|}{$\mathrm{VFA}, \mathrm{mol} / 100 \mathrm{~mol}$} \\
\hline \multirow[t]{2}{*}{ Acetate (A) } & HDS & 64.8 & 66.2 & 67.9 & 0.76 & $<0.01$ & 0.14 & 0.99 \\
\hline & LDS & 64.7 & 66.1 & 67.8 & & & & \\
\hline \multirow[t]{2}{*}{ Isobutyrate } & HDS & 1.06 & 1.83 & 1.71 & 0.24 & $<0.01$ & 0.62 & 0.98 \\
\hline & LDS & 1.07 & 1.83 & 1.71 & & & & \\
\hline \multirow[t]{2}{*}{ Butyrate } & HDS & 17.9 & 18.1 & 18.3 & 0.33 & $<0.01$ & 0.04 & 0.95 \\
\hline & LDS & 16.7 & 17.8 & 18.0 & & & & \\
\hline \multirow[t]{2}{*}{ Isovalerate } & HDS & 0.70 & 1.19 & 0.93 & 0.08 & $<0.01$ & 0.42 & 1.00 \\
\hline & LDS & 0.71 & 1.17 & 0.90 & & & & \\
\hline Valerate & HDS & 2.10 & 2.18 & 2.21 & 0.07 & $<0.01$ & 0.03 & 0.88 \\
\hline \multirow[t]{2}{*}{$\mathrm{pH}$} & HDS & 6.43 & 6.23 & 6.24 & 0.14 & $<0.01$ & 0.31 & 0.77 \\
\hline & LDS & 6.42 & 6.21 & 6.20 & & & & \\
\hline \multirow[t]{2}{*}{ Time below $\mathrm{pH} 6, \mathrm{~h}$} & HDS & 4.81 & 8.81 & 9.48 & 1.32 & $<0.01$ & 0.63 & 0.98 \\
\hline & LDS & 4.52 & 8.52 & 8.85 & & & & \\
\hline
\end{tabular}

*Significantly different $(P \leq 0.05)$ at the given time point.

$\dagger$ Tended to differ $(P<0.15)$ at the given time point. 
way. However, it is important to further scrutinize the tendency that was observed for trans-10 C18:1 during recovery.

Trans-11 C18:1 only tended to differ $(P=0.10)$ by treatment, with HDS treatments having an overall greater proportion of trans-11 C18:1. The trans-11 C18:1 isomer is associated with the normal $\mathrm{BH}$ pathway and is created from the desaturation of cis-9,trans-11 CLA (Harvatine et al., 2009a). A tendency existed for a treatment $\times$ day interaction $(P=0.13)$, where as day progresses, trans-11 C18:1 increases but is overall markedly lower for the LDS treatment. Rico et al. (2015a) reported milk trans-11 18:1 and cis-9,trans-11 CLA were decreased in control and low-fiber diets and increased in high-oil diets during recovery from MFD. This is counter to our observations, where trans-11 C18:1 tended to be greater with HDS. However, in the present study this was only a tendency $(P=0.10)$, and this has been reported to have a more significant effect when animals are fed a high RUFAL (Lascano et al., 2016) compared with the recovery diet in the present experiment. Cis-9, trans-11 was not influenced by treatment but tended $(P=0.08)$ to be greater for HDS on d 16. These results suggest that perhaps if $\mathrm{StK}_{\mathrm{d}}$ is not assessed when trying to recover cows from MFD, trans intermediates may continue to be produced, which can explain a lag in recovery of milk fat levels.

Rumen Fermentation. During recovery HDS tended to be greater in total VFA (Table 5; $P=0.10$ ). Lascano et al. (2016) reported a tendency for a decrease in total VFA in continuous cultures when $\mathrm{StK}_{\mathrm{d}}$ went from low to high; however, this is not reflected in the present study, where the HDS was higher in total VFA. The increase in total VFA concentration over time during recovery can be attributed to the increased DMI observed during this phase (Ramirez Ramirez et al., 2015) and the greater total VFA in the HDS treatment to the more readily available starch (Hatew et al., 2015).

Individual VFA were all affected by day (Table $5 ; P$ $<0.01)$. Acetate tended to be greater $(P=0.14)$ for HDS, which coincides with the report by Lascano et al. (2016), where acetate was increased with $\mathrm{StK}_{\mathrm{d}}$. In addition, propionate tended to be greater for HDS $(P$ $=0.14)$, similar to findings of Hatew et al. (2015). This observation is not surprising because it has been reported that the fermentation of starch primarily yields propionate rather than acetate and butyrate (Bannink et al., 2006). However, we attribute the effect of HDS on acetate and propionate molar proportions to the extent of fermentation triggered by $\mathrm{StK}_{\mathrm{d}}$. A more rapidly available starch source, similar to that provided in the HDS treatment, could increase substrate availability to rumen microbes and yield a greater proportion of propionate as seen in the present study. Isobutyrate and isovalerate were unaffected by treatment, but HDS-fed animals had greater valerate concentration as compared with LDS-fed animals $(P=0.03)$. Butyrate was also affected by treatment $(P=0.04)$, with greater concentrations being found in the HDS treatments during recovery. Changes in butyrate and valerate may be attributed to the source of corn in this experiment. These results are counter to those observed by Lascano et al. (2016), with higher StK $_{\mathrm{d}}$ yielding lower concentrations of butyrate, isobutyrate, and isovalerate in continuous culture with no absorption capability. The increase in total VFA along with no effect on rumen $\mathrm{pH}$ in the HDS animals can be explained by the higher observed butyrate molar proportion resulting in an induced increase in permeability of ruminal epithelia upregulating the absorption of acetate and propionate as well as the competitive absorption of total VFA (0.12 to $237.8 \mathrm{mmol} / \mathrm{h}$; Chibisa et al., 2015).

The A:P ratio was unchanged by treatment $(P=$ 0.30 ) but was noticeably greater during the recovery phase for both treatments. Rumen ammonia was altered by day $(P<0.01)$, with d 16 having greater $\mathrm{NH}_{3}-\mathrm{N}$ concentration for HDS. However, on d $22 \mathrm{NH}_{3}-\mathrm{N}$ concentration dropped to $<10 \mathrm{mg} / \mathrm{dL}$ for HDS, which was significantly lower than that for LDS. The drop in $\mathrm{NH}_{3}-\mathrm{N}$ concentration suggests that there may be a more efficient utilization of $\mathrm{N}$ for microbial protein synthesis and is also supported by the increased milk protein concentration on d 22 for HDS. The LDS treatment stayed consistent over time for $\mathrm{NH}_{3} \mathrm{~N}$ concentration and was significantly lower than HDS on d 16 but greater than HDS on d 22. Ramirez Ramirez et al. (2015) reported a decrease in $\mathrm{NH}_{3}-\mathrm{N}$ when starch was added to diets containing dried distillers grains, and this can be further reduced when highly fermentable carbohydrates are used in lactating cow rations (Chibisa et al., 2015). Greater $\mathrm{NH}_{3}-\mathrm{N}$ for HDS on d 16 and a subsequent decrease after d 22 suggest that using HDS during the recovery phase may cause a lag in microbial $\mathrm{N}$ capture and subsequent microbial protein synthesis. This may also alter microbial populations responsible for $\mathrm{BH}$, which can affect milk fatty acid composition and yield. However, microbial protein synthesis and microbial taxa analysis were not the aim of these investigations and, thus, not measured. Implications are therefore speculative.

Mean ruminal $\mathrm{pH}$ peaked at d 16 during recovery in both treatments (Figure 4). In addition, $\mathrm{pH}$ was similar between HDS and LDS during the recovery phase. Figure 5 illustrates the postprandial $\mathrm{pH}$ throughout the recovery phase, where a tendency $(P=0.08)$ existed 


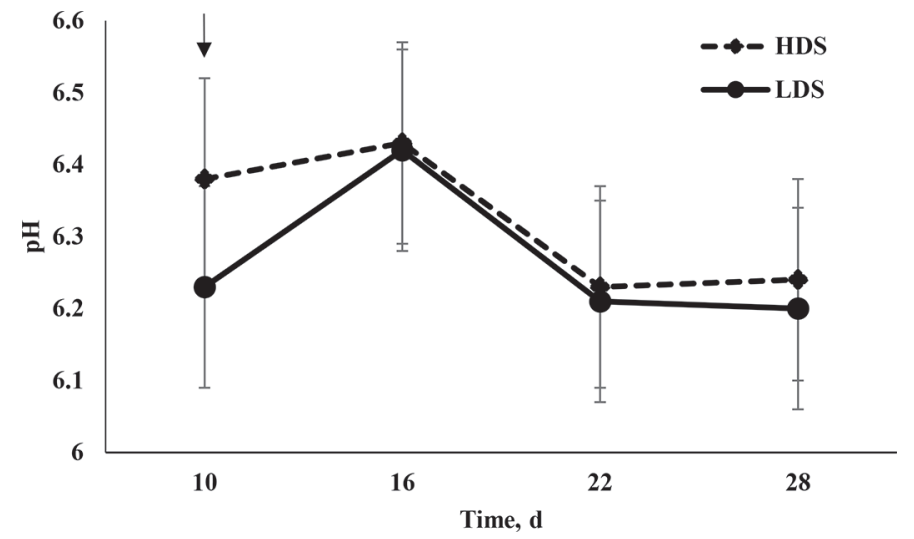

Figure 4. Mean $\mathrm{pH}$ values during recovery from diet-induced milk fat depression in cows fed HDS and LDS treatments. HDS = high degradable starch diet; LDS = low degradable starch diet. The arrow represents the end of induction and start of recovery. Error bars indicate SE.

for HDS to have lower rumen $\mathrm{pH} 4 \mathrm{~h}$ and $14 \mathrm{~h}$ after feeding. However, at 18, 20, and $22 \mathrm{~h}$ after feeding, rumen $\mathrm{pH}$ was significantly $(P=0.04)$ greater for the HDS treatment. The mean $\mathrm{pH}$ of rumen fluid was not affected by treatment but was affected by day (Table $5 ; P<0.01)$. Although mean ruminal $\mathrm{pH}$ was not affected by treatment, time below $\mathrm{pH} 6$ differed by day and can explain the lower $\mathrm{pH}$ observed on $\mathrm{d} 22$ and 28 in both treatments. The increase in rumen $\mathrm{pH}$ between treatments was not observed with mean rumen $\mathrm{pH}$ over time, but postprandial $\mathrm{pH}$ exhibited an hourly effect at hours 18, 20, and 22, where HDS was higher, similar to that reported by Lascano et al. (2016). The lack of significance in the mean rumen $\mathrm{pH}$ values could be attributed to the increased VFA absorption capacity as discussed earlier. In addition, diet fermentability may not affect ruminal $\mathrm{pH}$ if the buffering capacity in the rumen exceeds the production of VFA, which can be affected by chewing activity and salivary flow (Oba and Allen, 2003a). Increased ruminal production of trans-10,cis-12 CLA has been linked to low ruminal $\mathrm{pH}$, which is commonly found with high starch feeding and inadequate dietary fiber (Fuentes et al., 2009; Rico et al., 2015a). The link between rumen $\mathrm{pH}, \mathrm{BH}$, and milk fat has been extensively reported (AbuGhazaleh et al., 2005; Fuentes et al., 2009; Colman et al., 2012). Fuentes et al. (2009) reported that $\mathrm{pH}$ is the primary cause of the accumulation of trans-10 C18:1 and trans-10,cis-12 CLA in dual-flow continuous culture effluent. However, a previous experiment reported higher $\mathrm{pH}$ with a diet high in $\mathrm{StK}_{\mathrm{d}}$, yet a tendency to increase trans-10 C18:1 and trans-10,cis-12 CLA (Lascano et al., 2016), which suggests a pH-independent, substrate-dependent effect on $\mathrm{BH}$ intermediates when HDS is fed to continuous cultures and lactating cows.

Protozoa engulfment of starch granules has been proposed as an explanation to the effects observed in rumen $\mathrm{pH}$ when high starch concentrations and StKd are used (Hristov et al., 2001; Lascano et al., 2016). Protozoa play a major role in rumen symbiosis, and some species have a preference to engulf starch and thereby alter its degradation in the rumen (Goad et al., 1998). A treatment effect was observed for total rumen protozoal population $(P<0.01$; Table 6$)$. Total protozoa increased in both treatments between d 16 and 28 during recovery. Entodinium spp. and Epidinium spp. were reduced by day $(P<0.01)$ during the recovery phase. Populations of Entodinium spp. were significantly greater in ruminal contents for HDS-fed animals $(P=0.01)$. Certain genera of protozoa have a high affinity for certain substrates. For example, Entodinium spp. have been observed to have an extreme preference for starch, which supports the increase in this genera with HDS (Hungate, 1966). Other genera such as Dasytricha or Isotricha have been reported to accumulate with diets high in sugars (Van Soest, 1994). No treatment $\times$ day interaction was observed for the individual protozoa genera Epidinium spp., or either of the holotrich species belonging to Dasytricha spp. or Isotricha spp. In the case of the present study, if the starch was more available for engulfment, it is logical to see increases in these populations. The increase in Entodinium spp. for the HDS treatment can

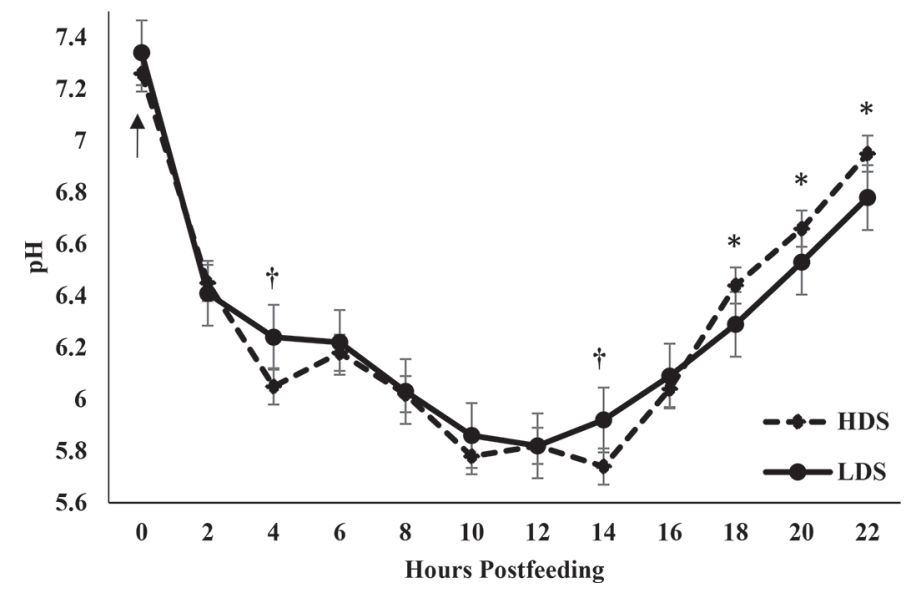

Figure 5. Postprandial $\mathrm{pH}$ values during recovery from diet-induced milk fat depression in cows fed HDS and LDS treatments. HDS = high degradable starch diet; LDS = low degradable starch diet. The arrow represents the end of induction and start of recovery. *Values were significantly different $(P \leq 0.05)$ at the given time point. †Values tended $(P<0.15)$ to differ at the given time point. Error bars indicate SE. 
Table 6. Protozoal populations of ruminal contents during recovery from diet-induced milk fat depression using a low degradable starch (LDS) or high degradable starch (HDS) diet

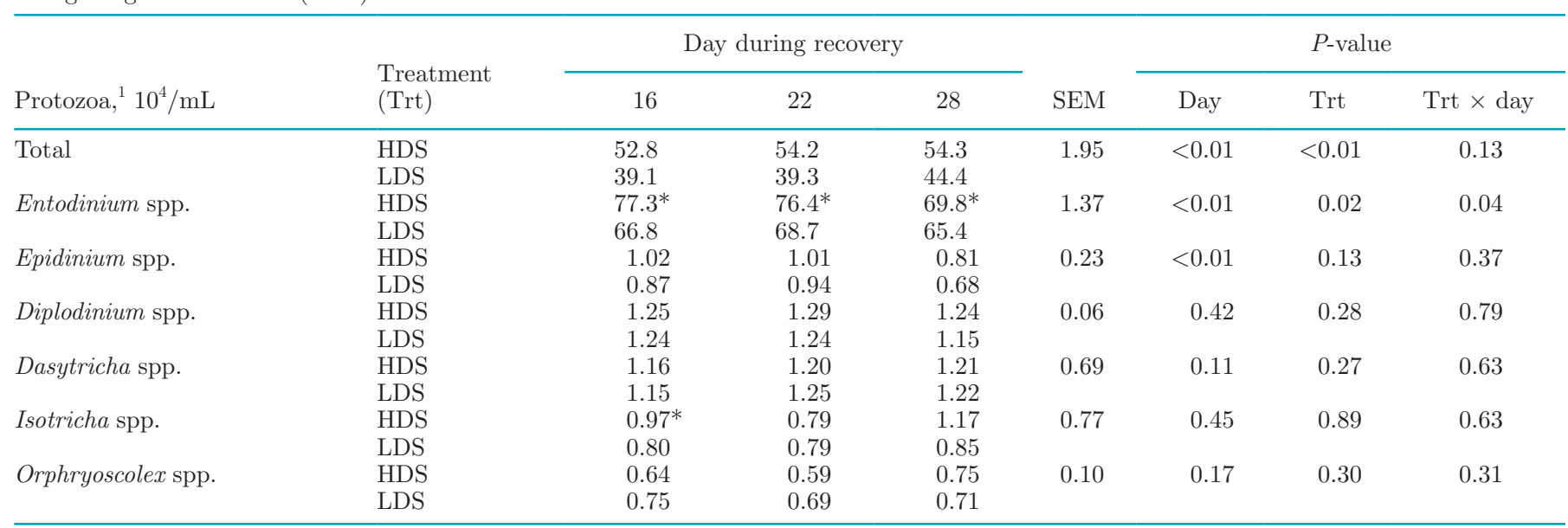

${ }^{1}$ Estimated according to the methods of Dehority (1993).

* Significantly different $(P \leq 0.05)$ at the given time point.

be explained by their close affiliation with feed particles and preference for starch (Russell, 2002). In addition, the greater total protozoa counts for HDS is consistent with high amounts of available starch in the rumen, as well as Entodinium spp. composing a large portion of the total protozoal mass (Hungate, 1966). Protozoa mass, even without any involvement in the $\mathrm{BH}$ of fatty acids, has been reported to account for between 30 and $43 \%$ of the CLA flowing to the duodenum (Lourenço et al., 2010). This complements the higher preformed milk FA observation for HDS, which may be caused by an enhanced flow of protozoal mass when dietary $\mathrm{StK}_{\mathrm{d}}$ is greater during the recovery period from MFD.

\section{CONCLUSIONS}

Substituting a high $\mathrm{StK}_{\mathrm{d}}$ source during the recovery phase results in similar recovery pattern and time with no effects on milk fat percentage compared with low degradable starch diets. However, milk fat yield tended to consistently be lower in HDS than in LDS on d 28, with shifts in milk FA composition and positional CLA isomers associated with milk fat inhibition. This suggests that the alternate pathway of $\mathrm{BH}$ still persists during recovery with HDS and evaluation, which is opposite to our initial hypothesis. Therefore, we conclude that amendments on starch concentration and PUFA during recovery may not be sufficient to recover from MFD if the recovery diet has a high $\mathrm{StK}_{\mathrm{d}}$.

\section{ACKNOWLEDGMENTS}

The authors thank members of the Clemson Ruminant Nutrition Team (Clemson, SC) and personnel at the LaMaster Dairy Farm (Clemson, SC) for their assistance throughout the duration of this project. Appreciation is extended to Mark Holt of Matrix Nutrition LLC (Chandler, AZ) for the donation of the high-degradable-starch corn used during this trial. This experiment was partially funded by Ascus Biosciences (San Diego, CA).

\section{REFERENCES}

AbuGhazaleh, A. A., M. B. Riley, E. E. Thies, and T. C. Jenkins. 2005. Dilution rate and $\mathrm{pH}$ effects of the conversion of oleic acid to trans C18:1 positional isomers in continuous culture. J. Dairy Sci. 88:4334-4341.

Albornoz, R. I., and M. S. Allen. 2018. Highly fermentable starch at different diet starch concentrations decreased feed intake and milk yield of cows in the early postpartum period. J. Dairy Sci. 101:8902-8915.

Allen, M. S. 2000. Effects of diet on short-term regulation of feed intake by lactating dairy cattle. J. Dairy Sci. 83:1598-1624.

Allen, M. S., R. A. Longuski, and Y. Ying. 2008. Endosperm type of dry ground corn grain affects ruminal and total tract digestion of starch in lactating dairy cows. J. Dairy Sci. 91(E. Suppl.):529.

AOAC. 1990. Official Methods of Analysis. 15th ed. Assoc. Off. Anal. Chem., Arlington, VA.

Bach Knudson, K. E. 1997. Carbohydrate and lignin contents of plant material used in animal feeding. Anim. Feed Sci. Technol. 67:319 338

Bailey, K. W., C. M. Jones, and A. J. Heinrichs. 2005. Economic returns to Holstein and Jersey herds under multiple component pricing. J. Dairy Sci. 88:2269-2280.

Bannink, A., J. Kogut, J. Dijkstra, J. France, E. Kebreab, A. M. Van Vuuren, and S. Tamminga. 2006. Estimation of the stoichiometry of volatile fatty acid production in the rumen of lactating cows. J. Theor. Biol. 238:36-51.

Bauman, D. E., and J. M. Griinari. 2001. Regulation and nutritional manipulation of milk fat: Low-fat milk syndrome. Livest. Prod. Sci. 70:15-29.

Baumgard, L. H., B. A. Corl, D. A. Dwyer, A. Saebo, and D. E. Bauman. 2000. Identification of the conjugated linoleic acid isomer that inhibits milk fat synthesis. Am. J. Physiol. Regul. Comp. Physiol. 278:R179-R184. 
Bradford, B. J., and M. S. Allen. 2004. Milk fat responses to a change in diet fermentability vary by production level in dairy cattle. J. Dairy Sci. 87:3800-3807.

Bradford, B. J., and M. S. Allen. 2005. Phlorizin administration increases hepatic gluconeogenic enzyme mRNA abundance but not feed intake in late-lactation dairy cows. J. Nutr. 135:2206-2211.

Chaney, A. L., and E. P. Marbach. 1962. Modified reagents for determination of urea and ammonia. Clin. Chem. 8:130-132.

Chibisa, G. E., P. Gorka, G. B. Penner, R. Berthiaume, and T Mutsvangwa. 2015. Effects of partial replacement of dietary starch from barley or corn with lactose on ruminal function, short-chain fatty acid absorption, nitrogen utilization, and production performance of dairy cows. J. Dairy Sci. 98:2627-2640.

Colman, E., B. M. Tas, W. Waegeman, B. De Baets, and V. Fievez. 2012. The logistic curve as a tool to describe the daily ruminal $\mathrm{pH}$ pattern and its link with milk fatty acids. J. Dairy Sci. 95:58455865

Danscher, A. M., L. Shucong, P. H. Andersen, E. Khafipour, N. B. Kristensen, and J. C. Plaizier. 2015. Indicators of induced subacute ruminal acidosis (SARA) in Danish Holstein cows. Acta Vet. Scand. 57:39.

Dehority, B. A. 1993. Laboratory Manual for Classification and Morphology of Rumen Ciliate Protozoa. CRC Press Inc., Boca Raton, FL.

Firkins, J. L., M. L. Eastridge, N. R. St-Pierre, and S. M. Noftsger. 2001. Effects of grain variability and processing on starch utilization by lactating dairy cattle. J. Anim. Sci. 79(E. Suppl):E218E238

Fuentes, M. C., S. Calsamiglia, P. W. Cardozo, and B. Vlaeminck. 2009. Effect of $\mathrm{pH}$ and level of concentrate in the diet on the production of biohydrogenation intermediates in a dual-flow continuous culture. J. Dairy Sci. 92:4456-4466.

Gama, M. A. S., P. C. Garnsworthy, J. M. Griinari, P. R. Leme, P. H M. Rodrigues, L. W. O. Souza, and D. P. D. Lanna. 2008. Dietinduced milk fat depression: Association with changes in milk fatty acid composition and fluidity of milk fat. Livest. Sci. 115:319-331.

Goad, D. W., C. L. Goad, and T. G. Nagaraja. 1998. Ruminal microbial and fermentative changes associated with experimentally induced subacute acidosis in steers. J. Anim. Sci. 76:234-241.

Harvatine, K. J., and M. S. Allen. 2006a. Effects of fatty acid supplements on feed intake, and feeding and chewing behavior of lactating dairy cows. J. Dairy Sci. 89:1104-1112.

Harvatine, K. J., and M. S. Allen. 2006b. Effects of fatty acid supplements on milk yield and energy balance of lactating dairy cows. J. Dairy Sci. 89:1081-1091.

Harvatine, K. J., Y. R. Boisclair, and D. E. Bauman. 2009a. Recent advances in the regulation of milk fat synthesis. Animal 3:40-54.

Harvatine, K. J., J. W. Perfield II, and D. E. Bauman. 2009b. Expression of enzymes and key regulators of lipid synthesis is upregulated in adipose tissue during CLA-induced milk fat depression in dairy cows. J. Nutr. 139:849-854.

Hatew, B., S. C. Podesta, H. Van Laar, W. F. Pellikaan, J. L. llis, J Dijkstra, and A. Bannink. 2015. Effects of dietary starch content and rate of fermentation on methane production in lactating dairy cows. J. Dairy Sci. 98:486-499.

Hristov, A. N., M. Ivan, L. M. Rode, and T. A. McAllister. 2001. Fermentation characteristics and ruminal ciliate protozoal populations in cattle fed medium- or high-concentrate barley-based diets. J. Anim. Sci. 79:515-524.

Hungate, R. E. 1966. The Rumen and Its Microbes. Acad. Press Inc., New York, NY.

Jenkins, T. C. 2010. Technical note: Common analytical errors yielding inaccurate results during analysis of fatty acids in feed and digesta samples. J. Dairy Sci. 93:1170-1174

Jenkins, T. C., V. Fellner, and R. K. McGuffey. 2003. Monensin by fat interactions on trans fatty acids in cultures of mixed ruminal microbes grown in continuous fermenters fed corn or barley. J. Dairy Sci. 86:324-330.

Jenkins, T. C., and K. J. Harvatine. 2014. Lipid feeding and milk fat depression. Vet. Clin. North Am. Food Anim. Pract. 30:623-642.
Kairenius, P., A. Ärölä, H. Leskinen, V. Toivonen, S. Ahvenjarvi, A. Vanhatalo, P. Huhtanen, T. Hurme, J. M. Griinari, and K. J. Shingfield. 2015. Dietary fish oil supplements depress milk fat yield and alter milk fatty acid composition in lactating cows fed grass silage-based diets. J. Dairy Sci. 98:5653-5671.

Lascano, G. J., M. Alende, L. E. Koch, and T. C. Jenkins. 2016. Changes in fermentation and biohydrogenation intermediates in continuous cultures fed low and high levels of fat with increasing rates of starch degradability. J. Dairy Sci. 99:6334-6341.

Littell, R. C., P. R. Henry, and C. B. Ammerman. 1998. Statistical analysis of repeated measures data using SAS procedures. J. Anim. Sci. 76:1216-1231.

Lopes, J. C., R. D. Shaver, P. C. Hoffman, M. S. Akins, S. J. Bertics, H. Gencoglu, and J. G. Coors. 2009. Type of corn endosperm influences nutrient digestibility in lactating dairy cows. J. Dairy Sci. 92:4541-4548.

Lourenço, M., E. Ramos-Morales, and R. Wallace. 2010. The role of microbes in rumen lipolysis and biohydrogenation and their manipulation. Animal 4:1008-1023.

Maia, M. R. G., L. C. Chaudhary, C. S. Bestwick, A. J. Richardson, N. McKain, T. R. Larson, I. A. Graham, and R. J. Wallace. 2010. Toxicity of unsaturated fatty acids to the biohydrogenating ruminal bacterium, Butyvibrio fibrisolvens. BMC Microbiol. 10:52.

Martinez, C. M., Y.-H. Chung, V. A. Ishler, K. W. Bailey, and G. A Varga. 2009. Effects of dietary forage level and monensin on lactation performance, digestibility and fecal excretion of nutrients, and efficiency of feed nitrogen utilization of Holstein dairy cows. J. Dairy Sci. 92:3211-3221.

Mathew, B., M. L. Eastridge, E. R. Oelker, J. L. Firkins, and S. K. R. Karnati. 2011. Interactions of monensin with dietary fat and carbohydrate components on ruminal fermentation and production responses by dairy cows. J. Dairy Sci. 94:396-409.

Maxin, G., H. Rulquin, and F. Glasser. 2011. Response of milk fat concentration and yield to nutrient supply in dairy cows. Animal 5:1299-1310.

Mohammed, R., J. Kennelly, J. Kramer, K. Beauchemin, C. Stanton, and J. Murphy. 2010. Effect of grain type and processing method on rumen fermentation and milk rumenic acid production. Animal 4:1425-1444.

Moody, M. L., G. I. Zanton, J. M. Daubert, and A. J. Heinrichs. 2007. Nutrient utilization of differing forage-to-concentrate ratios by growing Holstein heifers. J. Dairy Sci. 90:5580-5586.

Oba, M., and M. S. Allen. 2003a. Effects of corn grain conservation method on feeding behavior and productivity of lactating dairy cows at two dietary starch concentrations. J. Dairy Sci. 86:174183.

Oba, M., and M. S. Allen. 2003b. Effects of diet fermentability on efficiency of microbial nitrogen production in lactating dairy cows. J. Dairy Sci. 86:195-207.

Palmquist, D. L. 2006. Milk fat: origin of fatty acids and influence of nutritional factors thereon. Pages 43-92 in Advanced Dairy Chemistry, Vol. 2 Lipids. Springer, New York, NY.

Peterson, D. G., L. H. Baumgard, and D. E. Bauman. 2002. Short communication: Milk fat response to low doses of trans-10, cis-12 conjugated linoleic acid (CLA). J. Dairy Sci. 85:1764-1766.

Piperova, L. S., B. B. Teter, I. Bruckental, J. Sampugna, S. E. Mills, M. P. Yurawecz, J. Fritsche, K. Ku, and R. A. Erdman. 2000. Mammary lipogenic enzyme activity, trans fatty acids and conjugated linoleic acids are altered in lactating dairy cows fed a milk fat-depressing diet. J. Nutr. 130:2568-2574.

Ramirez Ramirez, H. A., E. Castillo Lopez, K. J. Harvatine, and P. J. Kononoff. 2015. Fat and starch as additive risk factors for milk fat depression in dairy diets containing corn dried distillers grains with solubles. J. Dairy Sci. 98:1903-1914.

Richards, C. J., F. F. Peterson, R. A. Britton, R. A. Stock, and C. R Krehbiel. 1995. In vitro starch disappearance procedure modifications. Anim. Feed Sci. Technol. 55:35-45.

Rico, D. E., and K. J. Harvatine. 2013. Induction of and recovery from milk fat depression occurs progressively in dairy cows switched between diets that differ in fiber and oil concentration. J. Dairy Sci. 96:6621-6630. 
Rico, D. E., A. W. Holloway, and K. J. Harvatine. 2015a. Effect of diet fermentability and unsaturated fatty acid concentration on recovery from diet-induced milk fat depression. J. Dairy Sci. 98:7930-7943

Rico, D. E., S. H. Preston, J. M. Risser, and K. J. Harvatine. 2015b. Rapid changes in key ruminal microbial populations during the induction of and recovery from diet-induced milk fat depression in dairy cows. Br. J. Nutr. 114:358-367.

Rico, D. E., Y. Ying, A. R. Clarke, and K. J. Harvatine. 2014. The effect of rumen digesta inoculation on the time course of recovery from classical diet-induced milk fat depression in dairy cows. J. Dairy Sci. 97:3752-3760.

Russell, J. B. 2002. Rumen Microbiology and Its Role in Ruminant Nutrition. Page 88. J. B. Russell Publ. Co., Ithaca, NY.

Shingfield, K. J., and J. M. Griinari. 2007. Role of biohydrogenation intermediates in milk fat depression. Eur. J. Lipid Sci. Technol. 109:799-816.

Shingfield, K. J., C. K. Reynolds, G. Hervas, J. M. Griinari, A. S. Grandison, and D. E. Beever. 2006. Examination of the persistency of milk fatty acid composition responses to fish oil and sunflower oil in the diet of dairy cows. J. Dairy Sci. 89:714-732.

Sveinbjörnsson, J., M. Murphy, and P. Uden. 2007. In vitro evaluation of starch degradation from feeds with or without various heat treatments. Anim. Feed Sci. Technol. 132:171-185.
Urrutia, N. L., and K. J. Harvatine. 2017. Acetate dose-dependently stimulates milk fat synthesis in lactating dairy cows. J. Nutr. 147:763-769.

Van Soest, P. J. 1994. Nutritional Ecology of the Ruminant. 2nd ed. Cornell Univ. Press, Ithaca, NY.

Van Soest, P. J., J. B. Robertson, and B. A. Lewis. 1991. Methods for dietary fiber, neutral detergent fiber, and nonstarch polysaccharides in relation to animal nutrition. J. Dairy Sci. 74:3583-3597.

Weiss, W. P., and J. M. Pinos-Rodriguez. 2009. Production responses of dairy cows when fed supplemental fat in low- and high-forage diets. J. Dairy Sci. 92:6144-6155.

Whitlock, L. A., D. J. Schingoethe, A. R. Hippen, K. F. Kalscheur, and A. A. AbuGhazaleh. 2003. Milk production and composition from cows fed high oil or conventional corn at two forage concentrations. J. Dairy Sci. 86:2428-2437.

Yang, C.-M. J., and G. A. Varga. 1989. Effect of three concentrate feeding frequencies on rumen protozoa, rumen digesta kinetics, and milk yield in dairy cows. J. Dairy Sci. 72:950-957.

Zened, A., F. Enjalbert, M. C. Nicot, and A. Troegeler-Meynadier. 2013. Starch plus sunflower oil addition to the diet of dry dairy cows results in a trans-11 to trans-10 shift of biohydrogenation. J. Dairy Sci. 96:451-459. 